\title{
ANALISIS KEMAMPUAN BERPIKIR ANALITIS DAN EVALUASI DALAM PEMBELAJARAN FISIKA PADA TOPIK USAHA DAN ENERGI
}

\author{
Nilah $^{\text {a) }}$ Liszulfah Roza ${ }^{\text {b) }}$ \\ Program Studi Pendidikan Fisika, Fakultas Keguruan dan Ilmu Pendidikan, Universitas Muhammadiyah Prof. \\ DR. HAMKA, Jl. Tanah Merdeka No.20, Kota Jakarta Timur, Daerah Khusus Ibukota Jakarta 13830, \\ Indonesia. \\ Email: a)nilahfaqoth@gmail.com, ${ }^{\text {b) }}$ liszulfahroza@gmail.com
}

\begin{abstract}
Abstrak
Penelitian ini bertujuan untuk mengetahui kemampuan berpikir analitis dan evaluasi siswa dalam memecahkan masalah fisika pada materi usaha dan energi. Metode penelitian yang digunakan yaitu deskripsi dengan pendekatan kuantitatif. Populasi pada penelitian ini seluruh siswa kelas X SMA X di Jakarta. Teknik pengambilan sampel menggunakan simple random sampling dan sampel yang digunakan sebanyak 15 siswa kelas X IPA pada semester genap tahun ajaran 2019/2020. Instrumen penelitian ini berupa tes kemampuan berpikir analitis dan evaluasi. Pengumpulan data dilakukan dengan tes dalam bentuk soal uraian sebanyak 15 butir yang mencakup indikator kemampuan berpikir analitis dan evaluasi dari taksonomi Bloom edisi revisi yaitu tingkat menganalisis (C4) dan mengevaluasi (C5). Dari analisis hasil test diperoleh hasil persentase siswa dalam menjawab soal dengan kemampuan berpikir analitis dan evaluasi tinggi sebesar 13,3\%, cukup analitis dan evaluasi sebesar 26,7 \%, dan kurang analitis dan evaluasi sebesar $60 \%$. Berdasarkan analisis data yang diperoleh, dapat disimpulkan bahwa tingkat kemampuan berpikir analitis dan evaluasi siswa kelas X IPA SMA X Jakarta pada semester genap tahun ajaran 2019/2020 dapat dikelompokkan pada kategori kelompok tinggi 13,3\%, kelompok sedang sebesar $26,7 \%$, dan kelompok rendah $60 \%$.
\end{abstract}

Kata-kata kunci: Pembelajaran fisika, kemampuan berpikir analitis dan evaluasi.

\begin{abstract}
This study aims to know students' analytical and evaluation thinking ability in solving physical problems in the chapter on work and energy. The research method used a description with a quantitative approach. The population in this study is the entire class X IPA X Senior High School in Jakarta. The sampling technique uses simple random sampling and the sample used is 15 students of class X IPA in the even semester of the academic year 2019/2020. The study instrument was in the form of analytical thinking and evaluation skills tests. Data collection is done with the test in the form of the description as much as 15 item questions that included indicators of analytical thinking ability and evaluation of the revised Bloom's taxonomy level of analysis (C4) and evaluate (C5). The analysis of the test results obtained the percentage of students in answering questions with high analytical thinking and evaluation ability by $13.3 \%$, sufficient analytical and evaluation by $26.7 \%$, and less analytical and evaluation by $60 \%$. Based on the analysis of the data obtained, it can be concluded that the level of analytical thinking ability and evaluation of students of class X IPA X at the one of Senior High School in Jakarta in the
\end{abstract}


even semester of the academic year 2019/2020 can be grouped in the high category $13.3 \%$, medium group at $26.7 \%$, and low group $60 \%$.

Keywords: Physics learning, ability of analytical and evaluation thinking

\section{PENDAHULUAN}

Mempelajari fisika menjadi suatu keharusan yang sangat penting dilakukan oleh setiap orang karena fisika adalah cabang sains paling dasar [1]. Fisika merupakan bagian dari ilmu alam yang jika ingin memecahkan permasalahan di dalamnya membutuhkan kemampuan berpikir [2], hal ini berarti kemampuan berpikir memegang peranan penting dalam pembelajaran khususnya dalam pembelajaran fisika. Pembelajaran fisika adalah proses menjadikan anak atau siswa belajar fisika. Belajar fisika dengan menggunakan metode yang relevan akan membantu siswa memperoleh pengetahuan, selain itu metode mengajar bermakna juga sebagai alat untuk menolong pelajar-pelajar memperoleh keterampilan, kebiasaan-kebiasaan, sikap-sikap, minat dan nilai-nilai yang diingainkan [3]. sehingga dapat mewujudkan salah satu tujuan pendidikan di abad 21 ini yaitu mendorong setiap individu agar mampu berpikir dalam memilih informasi yang valid dan relevan [4].

Di Indonesia masih memiliki banyak permasalahan yang harus dihadapi dalam rangka meningkatkan mutu pendidikan di Indonesia. Permasalahan ini dipengaruhi oleh sejumlah faktor eksternal yang berasal dari luar peserta didik, maupun faktor internal yang berasal dari dalam diri peserta didik itu sendiri [5] Oleh karena itu kegiatan belajar mengajar harus melibatkan kemampuan berpikir secara eksplisit, khusunya dalam pembelajaran fisika pada konsep usaha dan energi agar dapat memahami teori-teori dan membandingkannya dengan gejala dikehidupan sehari-hari dan dapat meningkatkan hasil belajar siswa.

Dalam bidang pendidikan, Taksonomi Bloom di rancang untuk membedakan kemampuan berpikir mulai dari tingkat terendah sampai dengan kemampuan berpikir tingkat tinggi. Kemudian Anderson dan Krathwohl merevisi taksonomi ini dengan mengklasifikasikan enam proses kognitif apakah siswa mampu atau belajar untuk mengingat (C1), memahami (C2), mengaplikasikan (C3), menganalisis (C4), mengevaluasi (C5) dan mengkreasi (C6). Menganalisis dan mengevaluasi merupakan bagian penting dalam kemampuan berpikir tingkat tinggi. Dalam penelitian ini kemampuan berpikir tingkat tinggi dibatasi pada kemampuan menganalisis dan mengevaluasi. Adapun dimensi proses kognitif untuk kemampuan analisis dan evaluasi adalah seperti terlihat pada tabel berikut. [2]

TABEL 1. Dimensi proses kognitif untuk kemampuan analisis dan evaluasi

\begin{tabular}{llll}
\hline $\begin{array}{l}\text { Kategori Kemampuan } \\
\text { Berpikir }\end{array}$ & \multicolumn{1}{c}{ Proses Kognitif } & \multicolumn{1}{c}{ Definisi } \\
\hline Analitis & 1. & Membedakan & $\begin{array}{l}\text { Membedakan bagian yang relevan atau penting dari bagian } \\
\text { materi yang disajikan yang tidak relevan atau tidak penting } \\
\text { Menentukan bagaimana elemen cocok atau berfungsi }\end{array}$ \\
& 2. $\quad$ Mengorganisasikan & $\begin{array}{l}\text { Malam suatu struktur } \\
\text { Menentukan sudut pandang, bias, nilai, atau maksud yang } \\
\text { mendasari materi yang disajikan }\end{array}$ \\
& 1. Menghubungkan & Memeriksa & $\begin{array}{l}\text { Mendeteksi inkonsistensi dalam suatu proses atau produk; } \\
\text { mendeteksi efektivitas suatu prosedur ketika sedang } \\
\text { dilaksanakan }\end{array}$ \\
& 2. Mengkritik & $\begin{array}{l}\text { Mendeteksi inkonsistensi antara produk dan kriteria } \\
\text { eksternal; mendeteksi kesesuaian prosedur untuk masalah } \\
\text { yang diberikan }\end{array}$ \\
& &
\end{tabular}


Menurut Krathwohl, menganalisis merupakan proses yang melibatkan proses memecah-mecah materi menjadi bagian-bagian kecil dan menentukan bagaimana hubungan antara bagian dan antara setiap bagian dan struktur keseluruhannya. Kategori proses menganalisis meliputi proses-proses kognitif membedakan, mengorganisasi, dan mengatribusikan. Tujuan-tujuan pendidikan yang diklasifikasikan dalam menganalisis mencakup belajar menentukan potongan-potongan informasi yang relevan dan penting (membedakan), menentukan cara-cara menata potongan-potongan informasi tersebut (mengorganisasikan) dan menentukan tujuan di balik informasi tersebut (mengatribusikan). Mengevaluasi didefinisikan sebagai suatu proses membuat keputusan berdasarkan kriteria standar. Kategori mengevaluasi mencakup proses-proses kognitif memeriksa keputusankeputusan yang diambil berdasarkan kriteria dan mengkritik keputusan keputusan tersebut [2].

Sudrajat mengartikan kemampuan analisis sebagai kemampuan individu untuk menentukan bagian-bagian dari suatu masalah dan menunjukkan hubungan antar bagian tersebut, melihat penyebab-penyebab dari suatu peristiwa atau memberi argumen-argumen yang menyokong suatu pernyataan [6]. Analytical thinking merupakan kemampuan memahami situasi permasalahan dengan cara memandangnya sebagai satu kesatuan mencakup kemampuan untuk mengidentifikasi masalah mendasar dalam situasi kompleks [7]. Evaluasi adalah proses mengumpulkan informasi mengenai objek evaluasi dengan membandingkannya dengan standar evaluasi [8]. Pendapat ini berarti bahwa evaluasi merupakan proses membandingkan objek evaluasi untuk mengumpulkan informasi. Menurut Suherman dalam [6] kemampuan evaluasi adalah kegiatan membuat penilaian berkenaan dengan nilai sebuah idea, kreasi, cara atau metode. Pendapat Suherman ini dapat diartikan bahwa kemampuan evaluasi merupakan aktivitas menilai sebuah idea, kreasi, cara atau metode.

Kemampuan berpikir analitis dan evaluasi menjadi bagian penting dalam pemecahan masalah fisika agar siswa dapat mengambil keputusan yang tepat dalam mejawab soal-soal sehingga dapat meningkatkan hasil belajar siswa. Selain itu, kemampuan berpikir analitis dan evaluasi sangat dibutuhkan di era perkembangan teknologi informasi yang semakin maju seperti yang terjadi saat ini. Berbagai informasi dapat di akses dengan bebas melalui internet dan tidak ada jaminan bahwa berita yang kita lihat tersebut adalah benar adanya. Terjadinya ledakan informasi dari berbagai sumber tersebut bisa jadi banyak yang ketinggalan zaman, tidak lengkap, atau tidak kredibel. Untuk dapat menggunakan informasi tersebut dengan baik, individu harus melakukan evaluasi terhadap data maupun sumber informasi [9].Melihat pentingnya peran dari kemampuan berpikir analitis dan evaluasi ini dalam upaya meningkatkan hasil belajar siswa dan menghadapi kemajuan teknologi informasi seperti saat ini maka perlu diadakan penelitian dengan tujuan mengukur tingkat kemampuan berpikir analitis dan evaluasi siswa dari data hasil belajar siswa dengan menggunakan tes soal uraian yang mencakup indikator kemampuan berpikir analitis dan evaluasi.

\section{METODOLOGI}

Penelitian ini menggunakan metode deskripsi dengan pendekatan kuantitatif. Penelitian ini dilaksanakan di salah satu SMA Swasta di Jakarta pada kelas X semester genap tahun pelajaran 2019/2020. Pada penelitian ini menggunakan sampel yang terdiri dari 15 siswa. Pengambilan sampel menggunakan teknik Simple Random Sampling. Tahap penelitian ini adalah perencanaan, pelaksanaan, dan pelaporan. Pada tahap perencanaan, peneliti mempersiapkan perangkat instrumen kemampuan berpikir analitis dan evaluasi siswa yang meliputi kisi-kisi soal, soal, kunci jawaban, dan pedoman penskoran. Kemampuan berpikir yang diukur pada penelitian ini meliputi aspek C4 (menganalisis), dan C5 (mengevaluasi). Instrumen tes dalam penelitian ini berbentuk uraian dan menggunakan indikator menurut revisi taksonomi Bloom oleh Anderson \& Krathwhol ada tiga macam proses kognitif yang tercakup dalam menganalisis mencakup: membedakan (differentiating), mengorganisir (organizing), dan menemukan pesan tersirat (attributing). Sedangkan untuk indikator kemampuan evalusi terdapat dua macam proses kognitif yang mencakup : memeriksa (checking) dan mengkritik (critiquing) [4].

Analisis kemampuan berpikir analitis dan evaluasi dilakukan dengan cara mengamati dan memeriksa pekerjaan siswa dalam menyelesaikan masalah dalam bentuk tes soal uraian. Data yang dipilih dari hasil jawaban siswa dengan kriteria jumlah siswa yang menjawab benar tepat dengan konsep, menjawab kurang tepat dengan konsep dan tidak menjawab sama sekali dari soal 
yang dibuat peneliti. Hal ini dilakukan untuk melihat perbedaan tingkat kemampuan berpikir analitis dan evaluasi siswa pada materi usaha dan energi dalam pembelajaran fisika di SMA.

TABEL 2. Tingkat Kemampuan Berpikir analitis dan evaluasi [10]

\begin{tabular}{ll}
\hline Tingkat Kemampuan & Rentang Nilai \\
\hline Tinggi & $76 \mathrm{~s} / \mathrm{d} 100$ \\
Sedang & $60 \mathrm{~s} / \mathrm{d} 75$ \\
Rendah & $0 \mathrm{~s} / \mathrm{d} 59$ \\
\hline
\end{tabular}

\section{HASIL DAN PEMBAHASAN}

Persentase capaian yang akan dicari pada penelitian ini adalah kemampuan berpikir analitis dan evaluasi sesuai dengan konsep Taksonomi Bloom yang direvisi oleh Anderson \& Krathwohl. Berdasarkan analisis data kemampuan menganalisis dan kemampuan mengevaluasi siswa dalam mengerjakan tes konsep usaha dan energi didapatkan data capaian seperti terlihat pada tabel 3 di bawah ini.

TABEL 3. Kemampuan Berpikir Analitis dan Evaluasi Siswa

\begin{tabular}{cccc}
\hline Tingkat Kemampuan menjawab soal & Jumlah siswa & Persentas(\%) & Rentang Nilai \\
\hline sangat analitis dan evaluasi & 2 & 13,3 & 76 s/d 100 \\
cukup analitis dan evaluasi & 4 & 26,7 & 60 s/d 75 \\
kurang analitis dan evaluasi & 9 & 60 & 0 s/d 59 \\
\hline \multicolumn{1}{c}{ Total } & $\mathbf{1 5}$ & &
\end{tabular}

Tabel 3 menunjukkan persentase dari jumlah hasil jawaban soal yang dapat dijawab siswa, baik itu persentase "sangat analitis dan evaluasi", "cukup analitis dan evaluasi" dan "kurang analitis dan evaluasi". Terlihat bahwa persentase siswa dengan kemampuan menjawab soal berpikir sangat analitis dan evaluasi adalah sebesar $13,3 \%$, cukup analitis dan evaluasi sebesar $26,7 \%$,dan kurang analitis dan evaluasi sebesar $60 \%$

Jumlah siswa dengan kriteria sangat baik berjumlah $0 \%$ dengan rentang nilai $90 \leq \mathrm{A} \leq 100$ dalam penelitian ini tidak ditemukan siswa yang mencapai nilai 90 sampai dengan 100. Hasil data yang diperoleh dalam rentang $75 \leq \mathrm{B}<90$ berjumlah 13,3\% dengan kriteria Baik. Hal ini dapat dikelompokkan ke dalam kategori kelompok tinggi. Pada rentang $55 \leq \mathrm{C}<75$ dengan kriteria cukup yaitu sebesar 26,7 \%, sehingga dapat dikelompokkan dalam kategori kelompok sedang. Sedangkan untuk kategori kelompok rendah berjumlah $60 \%$, pada kelompok rendah ada 2 kriteria hasil siswa yaitu kriteria kurang dan sangat kurang. Hal ini diperoleh dari hasil siswa untuk kriteria kurang dalam rentang $40 \leq \mathrm{D}<55$ yaitu sebesar $26,7 \%$, dan untuk kriteria Sangat kurang dalam rentang $0 \leq$ E $<40$ yaitu sebesar $33,3 \%$.

TABEL 4. Persentase Kriteria Kemampuan Berpikir Analitis dan Evaluasi Siswa

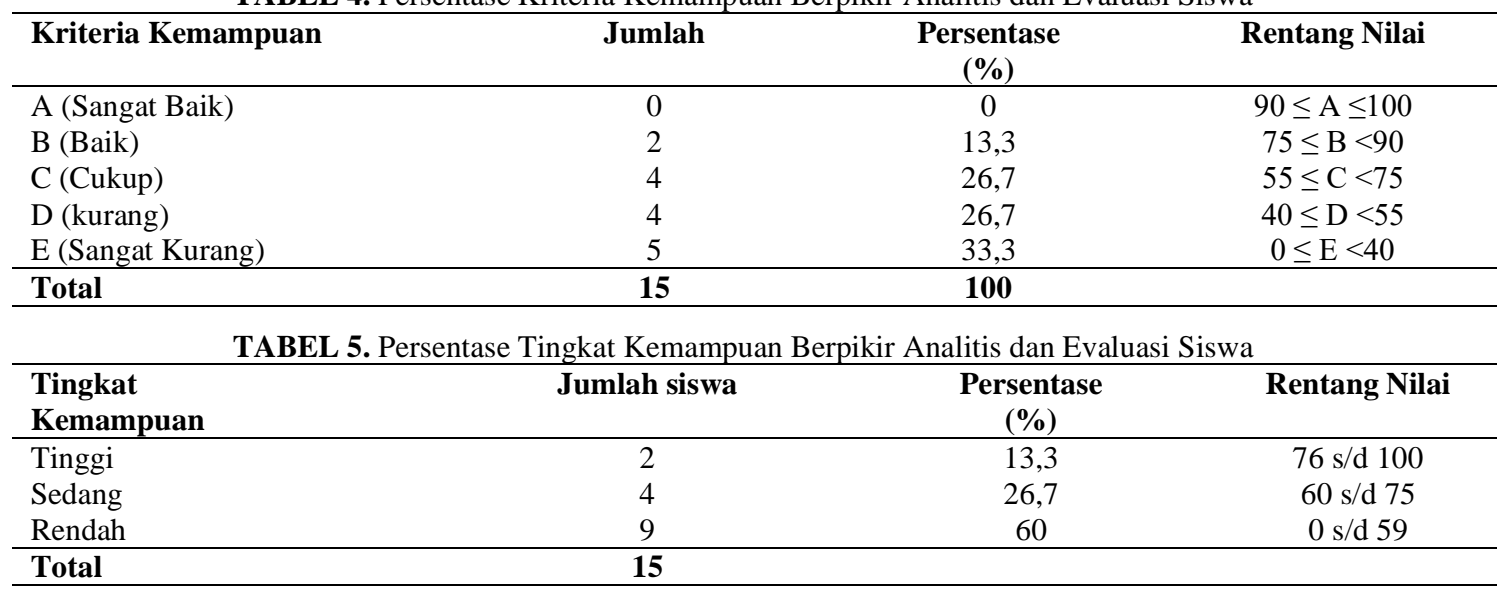

Persentase rata-rata tingkat kemampuan berpikir analitis dan evaluasi siswa, yaitu tingkat kemampuan berpikir analitis dan evaluasi kelompok tinggi sebesar 13,3\%, kelompok sedang sebesar $26,7 \%$, dan kelompok rendah sebesar $60 \%$. Berdasarkan hasil ini dapat disimpulkan bahwa siswa 
kelas X IPA di salah satu SMA X di Jakarta tahun pelajaran 2019/2020 memiliki kemampuan berpikir analitis dan evaluasi rendah.

Ciri-ciri soal Fisika harus logis dan sistematis. Permasalahan yang muncul dalam permasalahan tersebut bersumber dari suatu fenomena, kemudian diidentifikasi. Pada tahap identifikasi, masalah Fisika dianalisis untuk mencari konsep Fisika apa saja dan masalah Fisika apa saja yang muncul sehingga dapat ditemukan pemecahannya. Oleh karena itu, diperlukan stimulus pada setiap soal Fisika yang dapat menunjukkan suatu fenomena Fisika, kemudian dianalisis, hingga diperoleh solusi [11].

Pada salah satu jawaban siswa pada indikator membedakan (differentiating) menunjukan bahwa siswa mampu menunjukan perbedaan suatu konsep yang benar dan mampu memberikan alasan yang tepat akan tetapi kurang dilengkapi dengan pembuktian yang tepat sehingga dapat mengurangi skor maksimal dari soal yang diberikan. Dilihat pada salah satu jawaban siswa pada indikator mengorganisir (organizing) menunjukan bahwa siswa kurang mampu dalam menentukan cara-cara menata bagian-bagian informasi (mengorganisasikan) dari soal tersebut sehingga jawaban akhir tidak sesuai dengan apa yang ditanyakan pada soal tersebut. Dilihat pada salah satu jawaban siswa pada indikator menghubungkan (attributing) menunjukan bahwa siswa cukup mampu menentukan tujuan di balik informasi (menghubungkan) gambar dari soal tersebut namun tidak disertai dengan alasan berdasarkan konsep. Sehingga dapat mengurangi skor maksimal dari soal yang diberikan. Adapun pertanyaan yang memuat gambar dapat digunakan sebagai salah satu cara dalam mengevaluasi kemampuan representasi [12].

Pada salah satu jawaban siswa pada indikator memeriksa (checking) menunjukan bahwa siswa mampu memeriksa kebenaran dari berbagai pernyataan dan mampu memberikan alasan yang sesuai dengan konsep sehingga jawaban yang diberikan sangat sesuai dengan pertanyaan dari soal yang diberikan. Dilihat pada salah satu jawaban siswa pada indikator mengkritik (critiquing) menunjukan bahwa siswa mampu mengkritik pernyataan yang tidak sesuai dengan konsep yang diketahui dan mampu memberikan alasan yang sesuai dengan konsep sehingga jawaban yang diberikan sesuai dengan pertanyaan dari soal yang diberikan.

Berdasarkan hasil diagnosis kemampuan berpikir analitis dan evaluasi pada pokok bahasan usaha dan energi siswa kelas X, di dapatkan bahwa persentase rata-rata tingkat kemampuan berpikir analitis dan evaluasi siswa, yaitu tingkat kemampuan berpikir analitis dan evaluasi kelompok tinggi sebesar $13,3 \%$, kelompok sedang sebesar $26,7 \%$, dan kelompok rendah sebesar $60 \%$. Berdasarkan hasil ini dapat disimpulkan bahwa siswa kelas X IPA di salah satu SMA X di Jakarta tahun pelajaran 2019/2020 memiliki kemampuan berpikir kurang analitis dan evaluasi pada kelompok rendah. Walaupun demikian, guru dapat mengusahakan sebuah perlakuan agar siswa mengalami peningkatan dalam kemampuan kognitif pada pokok bahasan usaha dan energi. Salah satunya dengan menggunakan strategi pembelajaran writing to learn [13].

Berdasarkan hasil wawancara yang dilakukan, diketahui bahwa siswa kesulitan dalam mencapai indikator-indikator kemampuan berpikir analitis dan evaluasi. Adapun indikator kemampuan berpikir analitis yaitu: membedakan (differentiating), siswa mampu menjawab akan tetapi jawabannya kurang lengkap sehingga mengurangi skor, mengorganisir (organizing), siswa menjawab tidak runtut dan terstruktur sehinngga menyebabkan sebagian lankah menjawab benar dan sebagian salah, menghubungkan (attributing) siswa kurang terlatih dalam menjawab soal analitis sehingga susah untuk memahami pesan tersirat dalam soal.

Sedangkan untuk indikator kemampuan evalusi terdapat dua macam proses kognitif yang mencakup: memeriksa (checking) beberapa siswa masih kurang memahami konsep sehingga kesulitan dalam memeriksa kebenaran dari pernyataan pada soal, dan mengkritik (critiquing) sebagian siswa kurang memahami konsep sehingga kesulitan dalam menilai kebenaran dari pernyataan yang tidak sesuai konsep sehingga kurang percaya diri untuk memberikan sebuah kritik sebagai alasan untuk menguatkan jawaban. Mungkin dalam penerapannya nanti dapat ditambah kegiatan berdiskusi antar siswa. Pada tahap diskusi siswa diminta menganalisis dalil-dalil yang sesuai dengan masalah. Siswa dapat menganalisis berbagai argumen yang mendorong berfikir kritis [14]. Siswa bertukar ide dan informasi untuk mendapatkan alasan yang tepat. Diskusi kelompok membuat siswa lebih percaya diri dalam mengkomunikasikan alasan yang mereka gunakan untuk menguatkan jawaban [15]. 


\section{PENUTUP}

Siswa masih kesulitan dalam mencapai indikator-indikator kemampuan berpikir analitis dan evaluasi. Solusi yang dapat diberikan untuk mengatasi kesulitan siswa dalam mencapai indikatorindikator kemampuan berpikir analitis dan evaluasi yaitu:

1) Memberikan soal-soal yang non rutin yang dapat melatih kemampuan berpikir analitis dan kemampuan evaluasi

2) Melatih siswa agar lebih teliti dalam mengerjakan soal

3) Memberikan stimulus agar siswa dalam mengerjakan soal lebih terorganisir

4) Menggunakan metode pembelajaran yang mendukung siswa untuk mencapai indikatorindikator kemampuan berpikir analitis dan kemampuan evaluasi

5) Merancang media dan strategi pembelajaran yang mendukung siswa untuk mengembangkan kemampuan berpikir analitis dan kemampuan evaluasi

\section{REFERENSI}

[1] D. Giancoli, "Fisika : Prinsip dan Aplikasi," Jakarta: Erlangga, 2014.

[2] Winarti, "Profil Kemampuan Berpikir Analisis dan Evaluasi Mahasiswa dalam mengerjakan Soal Konsep Kalor," Jurnal Inovasi dan Pembelajaran Fisika, vol. 2, no. 1, pp. 19-24, 2015.

[3] M. D. Rahmawati, Sriyono and Ashari, "Analisis Keterampilan Berpikir Kritis Siswa pada Pembelajaran Fisika dengan Pendekatan Starter Eksperimen,” Radiasi, vol. 5, no. 1, pp. 7376, 2014.

[4] Afandi and Sadjidan, "Stimulasi keterampilan berpikir Tingkat Tinggi," Jawa tengah: UNS Press, 2018.

[5] I. I. Pratiwi, A.F. Chandra and T. R. Ramalis, "Penerapan PBL Dengan Konteks ESD untuk Meningkatkan Hasil Belajar Kognitif Peserta Didik," Prosiding Seminar Nasional Fisika (EJournal) $S N F$, vol. 8, pp. 1-8, 2019.

[6] D. Kurniati, R. Harimukti and N. A. Jamil, "Kemampuan Berpikir Tingkat tinggi Siswa SMP di Kabupaten Jember Dalam Menyelesaikan soal Berstandar PISA," Jurnal Penelitian dan Evaluasi Pendidikan, vol. 20, no. 2, pp. 142-155, 2016.

[7] T. Yuniarsih and Suwatno, "Manajemen Sumber Daya Manusia Teori, Aplikasi, dan Isu Penelitian," Bandung: Alfabeta, 2011.

[8] Wirawan, "Evaluasi Kinerja Sumber Daya Manusia Teori Aplikasi dan Penelitian," Jakarta: Salemba Empat, 2009.

[9] Susilowati, Sajidan and M. Ramli, "Analisis Keterampilan Berpikir Kritis Siswa Madrasah Aliyah Negeri di Kabupaten Magetan,” Prosiding Seminar Nasional Pendidikan Sains, pp. 223-231, 2017.

[10] S. Arikunto, “Dasar-dasar Evaluasi Pendidikan 2nd ed," Jakarta: Bumi Aksara, 2012.

[11] Y. Supriyati, R. Raihanati, and W. Nilawati, "The Development of Horizontal Anchor Items Test Tool by Rasch Model for Physics National Examination using Macromedia Flash", JPPPF (Jurnal Penelitian dan Pengembangan Pendidikan Fisika), vol. 6, no. 1, pp. 37 - 50, Jun. 2020.

[12] M. Masrifah, A. Setiawan, P. Sinaga, and W. Setiawan, "An Investigation of Physics Teachers' Multiple Representation Ability on Newton's Law Concept", JPPPF (Jurnal Penelitian dan Pengembangan Pendidikan Fisika), vol. 6, no. 1, pp. 105 - 112, Jun. 2020. 
[13] S. Nurazizah, P. Sinaga, and A. Jauhari, "Profil Kemampuan Kognitif dan Keterampilan Berpikir Kritis Siswa SMA pada Materi Usaha dan Energi", JPPPF (Jurnal Penelitian dan Pengembangan Pendidikan Fisika), vol. 3, no. 2, pp. 197 - 202, Dec. 2017.

[14] W. Sumarni, and S. Kadarwati, "Ethno-Stem Project-Based Learning: Its Impact to Critical and Creative Thinking Skills", Jurnal Pendidikan IPA Indonesia, vol. 9, no. 1, pp. $11-21,2020$.

[15] I. Arifin, I. Wilujeng, and J. Jumadi, “The Effect of Quick on The Draw Model Assisted by The Physics Learning Book Integrated Pancasila Values on Critical Thinking Skill", JPPPF (Jurnal Penelitian dan Pengembangan Pendidikan Fisika), vol. 6, no. 1, pp. 121 - 130, Jun. 2020. 
